Article

\title{
Ring-Opening Polymerization of 1,3-Benzoxazines via Borane Catalyst
}

\author{
Mustafa Arslan, Baris Kiskan * and Yusuf Yagci * \\ Department of Chemistry, Istanbul Technical University, Maslak, Istanbul 34469, Turkey; \\ mustafaarslan32@gmail.com \\ * Correspondence: kiskanb@itu.edu.tr (B.K.); yusuf@itu.edu.tr (Y.Y.); \\ Tel.: +90-212-385-6825 (B.K.); +90-212-285-3241 (Y.Y.)
}

Received: 13 February 2018; Accepted: 24 February 2018; Published: 27 February 2018

\begin{abstract}
Tris(pentafluorophenyl)borane was used as Lewis acid catalyst to lower the ring opening polymerization temperature (ROP) of 1,3-benzoxazines. Dynamic scanning calorimeter studies revealed that on-set ROP temperatures were decreased as much as $98^{\circ} \mathrm{C}$ for model benzoxazine compounds. Catalytic polymerization was traced by both FTIR and ${ }^{1} \mathrm{H}$ NMR, and revealed that tris(pentafluorophenyl)borane acted rapidly and fast curing achieved. Moreover, thermal properties of resulting polybenzoxazines were investigated by thermogravimetric analysis (TGA) and found out that the catalyst has high impact on char yield and even $3 \mathrm{~mol} \%$ catalyst augmented char yields up to $13 \%$.
\end{abstract}

Keywords: ring-opening polymerization; benzoxazines; polybenzoxazines; curing temperature; tris(pentafluorophenyl)borane

\section{Introduction}

Polybenzoxazines have attracted interest in the last decade due to superior properties in the field of high performance materials. These polymers can be considered as a class of phenolic thermosets resembling to novolac and resole type systems. Thus, they bear in many properties of traditional phenolics, such as excellent mechanical and thermal properties. Besides, polybenzoxazines exhibit unique features that makes them a contender to many high performance polymers. They have low water absorption, molecular design flexibility, and high char yield, and generally high glass transition temperatures [1-6]. Most of these features are mainly caused by the aminoalkyl repeat units $\left(-\mathrm{CH}_{2}-\mathrm{N}(\mathrm{R})-\mathrm{CH}_{2}-\right)$ and hydrogen bonds between amine and phenolic $-\mathrm{OH}$ groups [7-9]. Moreover, the cyclic structural nature of corresponding 1,3-benzoxazine monomers limit shrinkage during curing and also stabilize the monomer at a wide temperature range from room temperature to $c a .150{ }^{\circ} \mathrm{C}$, depending on the functionalities that are present on the monomer. [10] Thus, these monomers can be stored for prolonged times even under humid and relatively hot environment. The stability of oxazine ring, on the other hand, makes the polymerization be conducted at high temperatures that can be considered as a drawback [11]. Generally, polybenzoxazines are synthesized by thermally induced ring opening polymerization (ROP) of 1,3-benzoxazines over $220^{\circ} \mathrm{C}$ (Scheme 1). These values are higher than usual curing temperatures $\left(\mathrm{ca} .177^{\circ} \mathrm{C}\right)$ that are used to produce composites especially for aero-structures. Therefore, reduction in the cure temperature is highly desirable for industrial applications. 


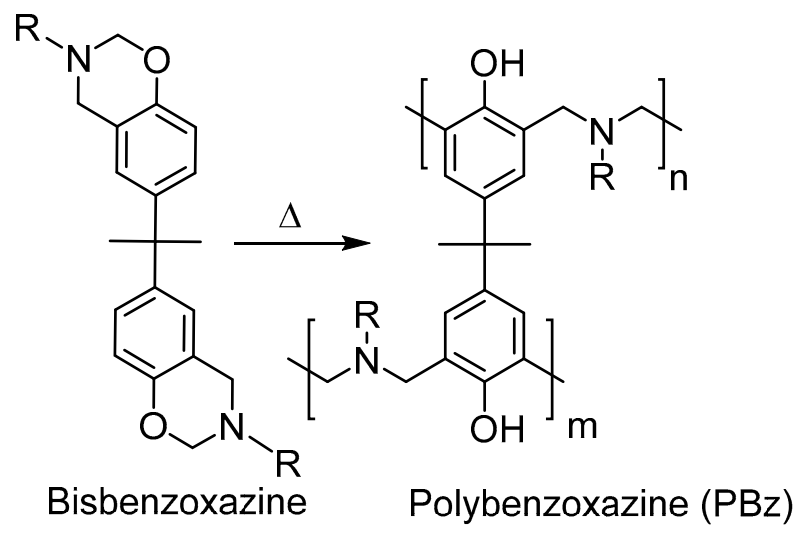

Scheme 1. Ring opening polymerization (ROP) of a bisbenzoxazine monomer.

The polymerization of benzoxazines proceeds through a cationic ring opening pathway where the oxygen and nitrogen on the heterocycle easily stabilizes the formed cations during the process [12-14]. This way, the distorted semi-chair oxazine ring is opened at high temperatures leading to Friedel-Crafts reaction at ortho or para position of aromatics. Actually, two major mechanistic paths take place according to the cation formation either on nitrogen or oxygen atoms that are on the oxazine ring. If the cation is formed on the oxygen atom of oxazine, then polybenzoxazine is thoroughly produced over ring-opening and Friedel-Crafts reactions. However, cation formation on the nitrogen atom causes ring-opening and subsequent etherification to give - $\mathrm{OH}$ blocked polybenzoxazine that eventually rearranges to form phenolic polybenzoxazine at high temperatures (Scheme 2) [15,16].

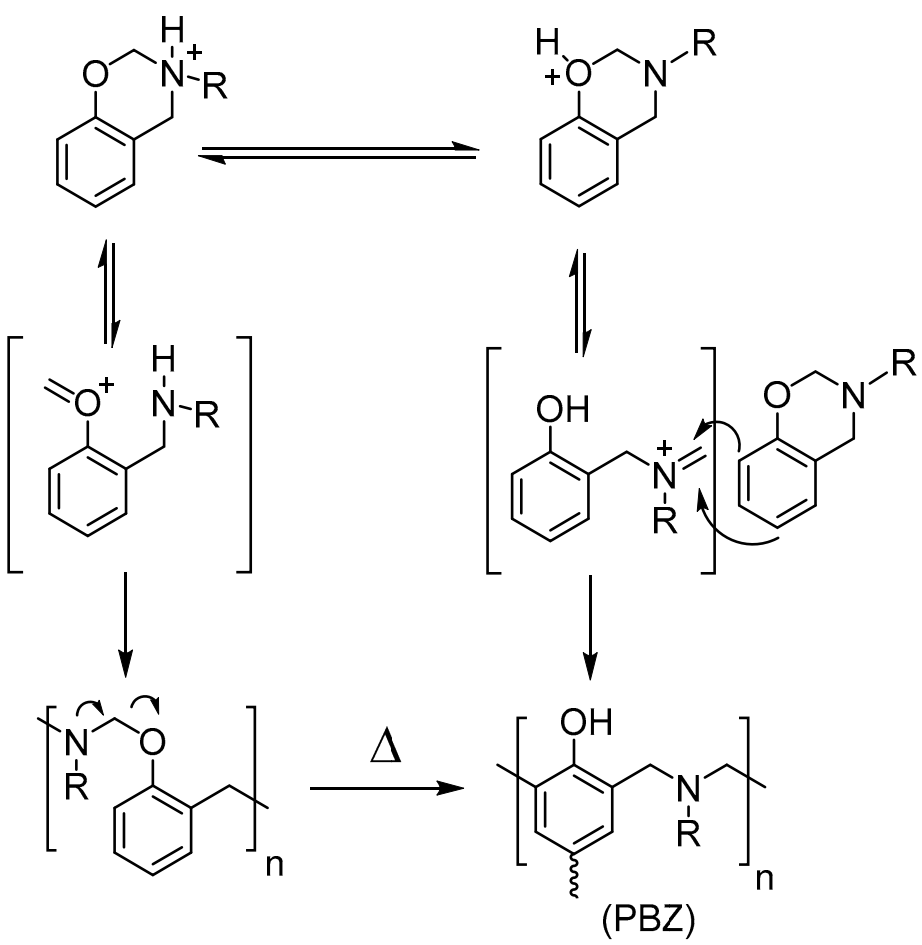

Scheme 2. Proposed mechanism for ROP of 1,3-benzoxazines.

The nature of polymerization of 1,3-benzoxazines is suitable to be catalysed by acids or other species that are able to produce cation on the oxazine ring. Designing self-catalytic monomers and admixing catalysts with benzoxazines are the usually applied strategies to reduce the curing temperature. Both approach has superiorities and drawbacks, thus selection may vary according to 
the specific application. For the first strategy, several different benzoxazine monomers containing $-\mathrm{COOH}$ and $-\mathrm{OH}$ groups were reported [17-21]. In this connection, it should be pointed out that although acidic groups readily reduce the ROP temperatures, decarboxylation observed during the polymerization causes voids in the final polymers due to released $\mathrm{CO}_{2}$ is the major deterrent of this strategy [22]. The materials formed this way may exhibit drastic mechanical failures in most applications. Therefore, carboxylic acid containing benzoxazines were best suited to produce sponge like networks, typically for chromatographic column applications. Alternative approach involving the use of -OH functional benzoxazines as self-catalysts appears to be more beneficial since problems associated with gas release is prevented [23]. The ROP temperature reductions were around $40{ }^{\circ} \mathrm{C}$ as the interaction of $-\mathrm{OH}$ groups with the cationic intermediates formed during ring opening process accelerates the polymerization. Notably, monomers with unoccupied phenolic -OH groups act as built-in catalysts and effectively reduce ROP temperatures which can be considered as an alternative solution to harsh curing conditions [24]. Actually, the described self-catalyst strategy is designed for the systems that contain only benzoxazines and derivatives. On the other hand, this approach needs synthesis of structurally related monomers and for some monomers multi step synthetic routes may be required. As stated, the second strategy, based on addition of catalysts into benzoxazine formulations, appears to be easier and more flexible. Several compounds, namely amines, amine salts, thiols, phenols, toluene sulfonates, and colloidal sulfur were used to promote ROP of benzoxazines [25-33]. Moreover, admixing Lewis acids with benzoxazines profoundly affected the curing and ROP temperatures were drastically reduced down to $120-160{ }^{\circ} \mathrm{C}$. Typically, $\mathrm{PCl}_{5}, \mathrm{POCl}_{3}, \mathrm{TiCl}_{4}, \mathrm{AlCl}_{3}$, and $\mathrm{FeCl}_{3}$ acted as efficient catalysts, particularly when with solvents and ring opening of oxazine took place even at room temperature [34-36]. Although these catalysts are economical and potent, their miscibility in neat benzoxazines is limited. Therefore, Lewis acids in complex structures would obviously increase both their solubility and stabilities. Acetylacetonato complexes of 4th period transition metals can be given as a striking example in this context. These complexes with nucleophiles promote the polymerization efficiently and $120^{\circ} \mathrm{C}$ as onset of ROP temperatures were obtained [37]. Highly active catalytic nature of Lewis acid often initiate ROP at low temperatures and viscosity increases rapidly, providing a practical advantage for fast curing requirements. Thus, miscibility of the Lewis catalyst come into prominence for such purposes and tris(pentafluorophenyl)borane $\left(B\left(\mathrm{C}_{6} \mathrm{~F}_{5}\right)_{3}\right)$ has a potential in this manner. It was generally used to catalyse several organic reactions and it also played role in borylation chemistry [38]. For example, substituted quinolones were synthesized by $\mathrm{B}\left(\mathrm{C}_{6} \mathrm{~F}_{5}\right)_{3}$ initiated aldehyde-aniline-alkyne reaction [39]. Moreover, $\mathrm{B}\left(\mathrm{C}_{6} \mathrm{~F}_{5}\right)_{3}$ was shown to be an excellent activator component in homogeneous Ziegler-Natta processes [40]. Besides its catalytic activity, this acid was used to prepare carbonyl-borane adducts showing solid state luminescence [41] and also as receptor to detect $\mathrm{NH}_{3}$ on an organic field-effect transistor [42]. The multirole of $\left.\mathrm{B}_{(} \mathrm{C}_{6} \mathrm{~F}_{5}\right)_{3}$ prompted us to further extend its usage in other areas particularly in benzoxazine based thermosets. Herein, we present our investigations for the impact of the $\mathrm{B}\left(\mathrm{C}_{6} \mathrm{~F}_{5}\right)_{3}$ on ROP of benzoxazines.

\section{Materials and Methods}

\subsection{Materials}

4,4'-Isopropylidenediphenol (bisphenol A) (Aldrich, 97\%, St. Louis, MO, USA), aniline (Aldrich, $\geq 99.5 \%$, St. Louis, MO, USA) paraformaldehyde (Acros, $96 \%$, Geel, Belgium), benzylamine (Aldrich, 99\%), 4-tert-butylphenol (Aldrich, 99\%, St. Louis, MO, USA), butylamine (Aldrich, $\geq 99 \%$, St. Louis, MO, USA), xylenes (Aldrich, $\geq 96 \%$, St. Louis, MO, USA), ethanol (Aldrich, $\geq 99.5 \%$, St. Louis, MO, USA), toluene (Carlo Erba, 99.5\%, Barcelona, Spain), tetrahydrofuran (Sigma-Aldrich, $\geq 99 \%$, St. Louis, MO, USA), hexane (Aldrich, 95\%, St. Louis, MO, USA), and diethyl ether (Aldrich, $\geq 98 \%$, St. Louis, MO, USA), sodium hydroxide (Sigma-Aldrich, $\geq 98 \%$, St. Louis, MO, USA) were used as received. 


\subsection{Characterization}

All ${ }^{1} \mathrm{H}$ NMR spectra were recorded on an Agilent NMR System VNMRS 500 spectrometer (Agilent, Santa Clara, CA, USA) at room temperature in $\mathrm{CDCl}_{3}$ with $\mathrm{Si}\left(\mathrm{CH}_{3}\right)_{4}$ as an internal standard. FT-IR spectra were recorded on a Perkin-Elmer FT-IR Spectrum (Boston, MA, USA) One spectrometer. Differential Scanning Calorimetry (DSC) was performed on Perkin-Elmer Diamond DSC from 0 to $320{ }^{\circ} \mathrm{C}$, with a heating rate of $10^{\circ} \mathrm{C} / \mathrm{min}$. under nitrogen flow. Thermal gravimetric analysis (TGA) was performed on Perkin-Elmer Diamond TA/TGA with a heating rate of $10^{\circ} \mathrm{C} / \mathrm{min}$ under nitrogen flow. Gel permeation chromatography (GPC) measurements were performed on a Viscotek GPC max auto sampler system (Malvern, UK) consisting of a pump, a Viscotek UV detector, and Viscotek a differential refractive index (RI) detector with three ViscoGEL GPC columns (G2000H HR, G3000H $\mathrm{HR}$, and G4000H HR, $7.8 \mathrm{~mm}$ internal diameter, $300 \mathrm{~mm}$ length) in series. Tetrahydrofuran (THF) was used as an eluent at flow rate of $1.0 \mathrm{~mL} \cdot \mathrm{min}^{-1}$ at $30^{\circ} \mathrm{C}$. Both of the detectors were calibrated with PS standards having narrow-molecular-weight distribution. Data were analysed using ViscotekOmniSEC Omni-01 software (Malvern, UK).

\subsection{Synthesis of Aniline Based Bisbenzoxazine (B-a)}

In a $100 \mathrm{~mL}$ round bottomed flask, paraformaldehyde ( $34.9 \mathrm{mmol}, 1.05 \mathrm{~g})$, bisphenol A ( $8.76 \mathrm{mmol}$, $2.0 \mathrm{~g})$, and aniline $(17.5 \mathrm{mmol}, 1.6 \mathrm{~mL}$ ) were dissolved with $20 \mathrm{~mL}$ of xylenes. The reaction mixture was heated to $120^{\circ} \mathrm{C}$ for $12 \mathrm{~h}$. The solvent was evaporated under vacuum. The resulting oily product was dissolved in diethyl ether $(200 \mathrm{~mL})$ and extracted with $3 \mathrm{M}$ sodium hydroxide for three times to remove unreacted bisphenol $\mathrm{A}$. Then, to neutralize the solution diethyl ether solution washed with distilled water $(150 \mathrm{~mL})$ for three times. The solution was dried with anhydrous $\mathrm{Na}_{2} \mathrm{SO}_{4}$ and filtered. Diethyl ether was evaporated under vacuum. The product was dried under vacuum at room temperature for $24 \mathrm{~h}$.

\subsection{Synthesis of Benzylamine Based Monobenzoxazine (P-Bn)}

In a $100 \mathrm{~mL}$ round bottomed flask, paraformaldehyde (106 mmol, $3.19 \mathrm{~g})$, phenol (53.1 mmol, $5.0 \mathrm{~g}$ ), and benzylamine $(53.1 \mathrm{mmol}, 5.80 \mathrm{~mL}$ ) were dissolved with $50 \mathrm{~mL}$ of toluene and $25 \mathrm{~mL}$ of ethanol mixture. The reaction mixture was refluxed for $12 \mathrm{~h}$. The solvent was evaporated under vacuum. The resulting oily product was dissolved in diethyl ether $(200 \mathrm{~mL})$ and extracted with $3 \mathrm{M}$ sodium hydroxide for various times to remove unreacted bisphenol A. Then, to neutralize the solution diethyl ether solution washed with distilled water $(150 \mathrm{~mL})$ for three times. The solution was dried with anhydrous $\mathrm{Na}_{2} \mathrm{SO}_{4}$ and filtered. Diethyl ether was evaporated under vacuum. The product was dried under vacuum at room temperature for $24 \mathrm{~h}$.

\subsection{Synthesis of 4-t-butylphenol Based Monobenzoxazine (t-P-Bt)}

4-t-Butylphenol $(5.0 \mathrm{~g}, 33.3 \mathrm{mmol})$ was added to a $100 \mathrm{~mL}$ round bottomed flask and cooled to $0{ }^{\circ} \mathrm{C}$ in an ice-bath. Butylamine $(2.43 \mathrm{~g}, 33.3 \mathrm{mmol})$ was added dropwise to 4-tert-butylphenol for $15 \mathrm{~min}$. and stirred for $5 \mathrm{~min}$. Paraformaldehyde $(1.99 \mathrm{~g}, 66.4 \mathrm{mmol})$ was added partly to the mixture over $20 \mathrm{~min}$ with stirring at $0{ }^{\circ} \mathrm{C}$. After the mixture was stirred over $15 \mathrm{~min}$. at room temperature, temperature was raised to $105^{\circ} \mathrm{C}$ and stirred for $2 \mathrm{~h}$. The reaction medium cooled to room temperature, dissolved in diethyl ether and extracted with aqueous sodium hydroxide (10 wt \%, $250 \mathrm{~mL})$, two times with distilled water and dried with magnesium sulfate. The product was dried under vacuum at room temperature for $24 \mathrm{~h}$.

\section{Results and Discussion}

As stated, previous studies on the ROP mechanism of benzoxazines disclosed that the polymerization is initiated by thermally induced formation of cationic intermediates on $\mathrm{N}-$ and $\mathrm{O}-$ atoms, followed by the concurrent cleavage of methylene bridge on the oxazine ring. The formed 
cationic species immediately attack $\mathrm{N}-, \mathrm{O}-$, or aryl group and the rearrangement of labile bonds finally produce polybenzoxazines. In such a polymerization mechanism, Lewis acids are appropriate to consider as effective catalyst system since Lewis acids can strongly bind and generate cationic species on nitrogen and oxygen atoms of oxazine ring. Thus, the energy requirement for cleaving the oxazine ring reduces drastically and the ROP temperature decrease becomes imminent. It should be noted that the solubility of many Lewis acids are limited in organic compounds, and thus, in a benzoxazine medium, the solubility of the acid and polarity of benzoxazine monomer would affect the catalyst performance. Therefore, preparation of benzoxazine based formulations containing Lewis acids, such as $\mathrm{FeCl}_{3}, \mathrm{TiCl}_{4}, \mathrm{AlCl}_{3}, \mathrm{ZnCl}_{2}$ can be problematic due to their low solubility in organic solvents. Alternatively, ligated Lewis acids may provide better solubility and catalytic activity. Apart from solubility issues, boron compounds are known to show high complexation affinity against amines and oxazine ring bearing tertiary amine in its structure, which would presumably strongly bind central boron atom of a boron based Lewis acid [43]. It seemed, therefore, appropriate to investigate the catalytic activity of $\mathrm{B}\left(\mathrm{C}_{6} \mathrm{~F}_{5}\right)_{3}$ on the ROP of benzoxazines. Initially, mono and bisbenzoxazines were synthesized as model monomers by using conventional method, according to the literature (Scheme 3) [44-46]. Spectral characterization of these monomers was performed using ${ }^{1} \mathrm{H}$ NMR analysis (Figures S1-S3).

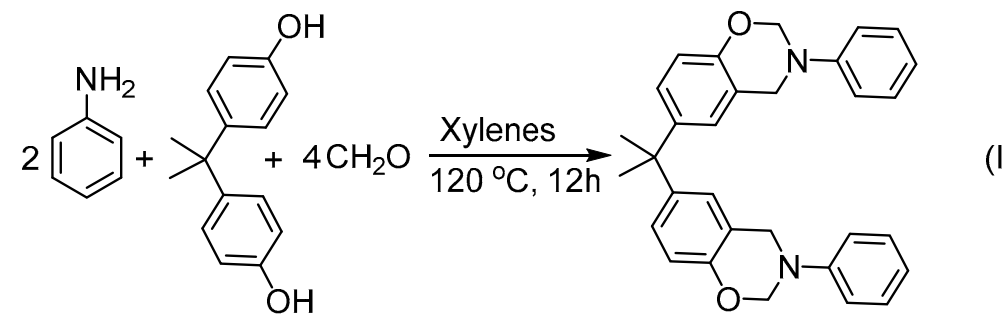

(B-a)

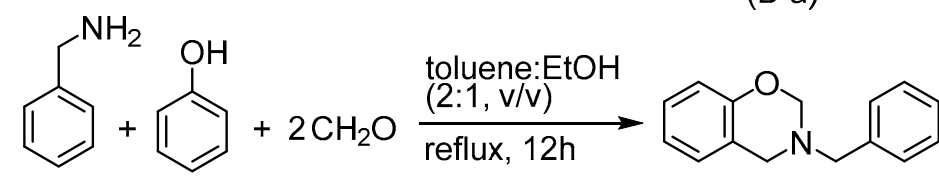

$(\mathrm{P}-\mathrm{Bn})$<smiles>CCCCN1COc2ccc(C(C)(C)CC3CCCCC3COc3ccccc3)cc2C1</smiles>

Scheme 3. Synthesis of B-a, P-Bn, t-P-Bt monomers.

Typically, the catalyst was admixed with benzoxazine monomers in either 3 or $5 \mathrm{~mol} \%$ by dissolving the components in tetrahydrofuran $(1 \mathrm{~mL})$ to obtain homogeneous mixtures. The solvent in the mixtures were removed by blowing nitrogen gas and then subjected to vacuum $(c a .10 \mathrm{~mm}-\mathrm{Hg})$ for $5 \mathrm{~min}$. at room temperature. As is known, most of the benzoxazines have the ROP temperatures (curing maximum, $T_{\max }$ ) generally over $220^{\circ} \mathrm{C}$, which can be monitored as a distinct exotherm. Thus, ROP of B-a and P-Bn with $\mathrm{B}\left(\mathrm{C}_{6} \mathrm{~F}_{5}\right)_{3}$ were traced under $\mathrm{N}_{2}$ environment with a heating rate of $10{ }^{\circ} \mathrm{C} \cdot \mathrm{min}^{-1}$ using a DSC device. The overlaid DSC thermograms for benzoxazine/catalyst mixtures presented in Figures 1 and 2 and DSC data tabulated in Table 1 clearly show the ROP temperature reduction of these monomers with added $\mathrm{B}\left(\mathrm{C}_{6} \mathrm{~F}_{5}\right)_{3}$. Moreover, the impact of catalyst amount on the ROP was also examined by increasing the $\mathrm{B}\left(\mathrm{C}_{6} \mathrm{~F}_{5}\right)_{3}$ content from 3 to $10 \mathrm{~mol} \%$ and the on-set of curing temperatures dropped to 125 from $212{ }^{\circ} \mathrm{C}$ for B-a and 163 from $242{ }^{\circ} \mathrm{C}$ for P-Bn (Figures 1 and 2), corresponding to 98 and $81^{\circ} \mathrm{C}$ reduction on on-set curing temperature, respectively. 


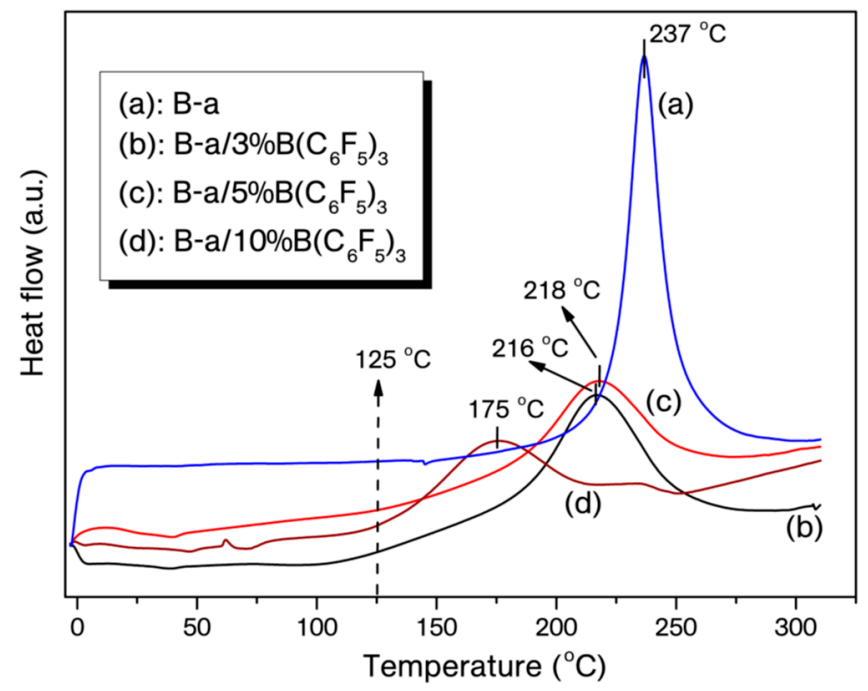

Figure 1. Differential Scanning Calorimetry (DSC) thermograms of pristine $\mathrm{B}-\mathrm{a}(\mathrm{a}), \mathrm{B}-\mathrm{a} / 3 \% \mathrm{~B}\left(\mathrm{C}_{6} \mathrm{~F}_{5}\right)_{3}$ (b), B-a $/ 5 \% B\left(\mathrm{C}_{6} \mathrm{~F}_{5}\right)_{3}(\mathbf{c}), \mathrm{B}-\mathrm{a} / 10 \% \mathrm{~B}\left(\mathrm{C}_{6} \mathrm{~F}_{5}\right)_{3}(\mathrm{~d})$.

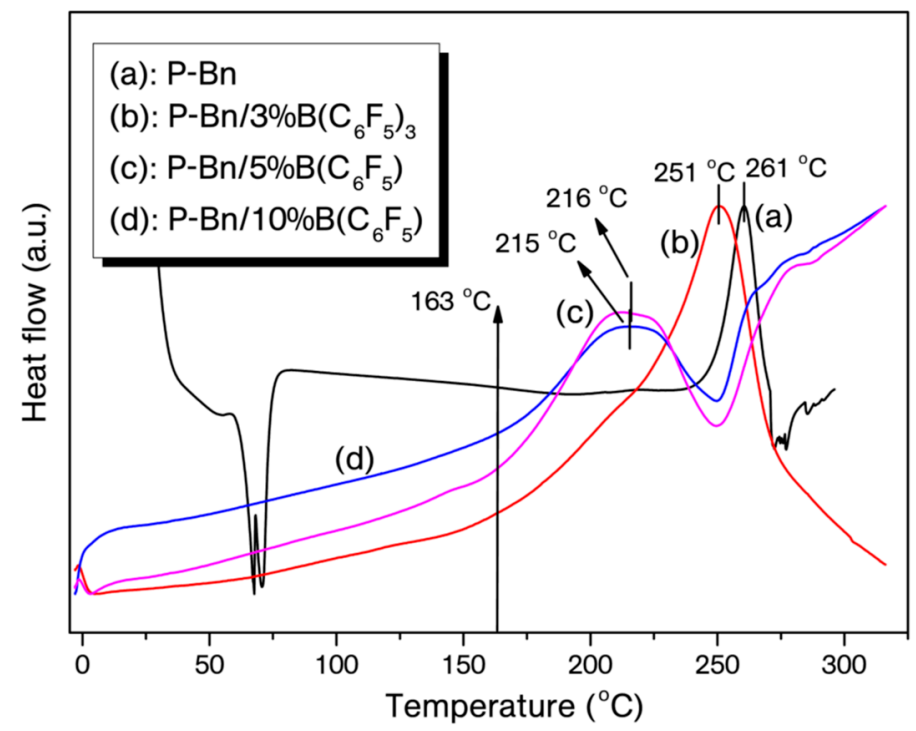

Figure 2. DSC thermograms of pristine $\mathrm{P}-\mathrm{Bn}(\mathbf{a}), \mathrm{P}-\mathrm{Bn} / 3 \% \mathrm{~B}\left(\mathrm{C}_{6} \mathrm{~F}_{5}\right)_{3}(\mathbf{b}), \mathrm{P}-\mathrm{Bn} / 5 \% \mathrm{~B}\left(\mathrm{C}_{6} \mathrm{~F}_{5}\right)_{3}$ (c), $\mathrm{P}-\mathrm{Bn} / 10 \% \mathrm{~B}\left(\mathrm{C}_{6} \mathrm{~F}_{5}\right)_{3}(\mathrm{~d})$.

Table 1. DSC ${ }^{\mathrm{a}}$ characteristics of $\mathrm{B}-\mathrm{a}, \mathrm{P}-\mathrm{Bn}$ and their mixtures with various amounts of $\mathrm{B}\left(\mathrm{C}_{6} \mathrm{~F}_{5}\right)_{3}$.

\begin{tabular}{ccccc}
\hline Entry & $\begin{array}{c}\text { On-Set of } \\
\text { Curing }\left({ }^{\circ} \mathrm{C}\right)\end{array}$ & $\begin{array}{c}\text { End-Set of } \\
\text { Curing }\left({ }^{\circ} \mathrm{C}\right)\end{array}$ & $\begin{array}{c}\text { Maximum } \\
\text { Curing }\left({ }^{\circ} \mathrm{C}\right)\end{array}$ & $\boldsymbol{\Delta H}(\mathbf{J} / \mathbf{g})$ \\
\hline $\mathrm{B}-\mathrm{a}$ & 212 & 266 & 237 & -201 \\
$\mathrm{~B}-\mathrm{a} / 3 \% \mathrm{~B}\left(\mathrm{C}_{6} \mathrm{~F}_{5}\right)_{3}$ & 180 & 251 & 216 & -156 \\
$\mathrm{~B}-\mathrm{a} / 5 \% \mathrm{~B}\left(\mathrm{C}_{6} \mathrm{~F}_{5}\right)_{3}$ & 180 & 252 & 217 & -117 \\
$\mathrm{~B}-\mathrm{a} / 10 \% \mathrm{~B}\left(\mathrm{C}_{6} \mathrm{~F}_{5}\right)_{3}$ & 125 & 216 & 174 & -103 \\
$\mathrm{P}-\mathrm{Bn}$ & 242 & 272 & 261 & -35 \\
$\mathrm{P}-\mathrm{Bn} / 3 \% \mathrm{~B}\left(\mathrm{C}_{6} \mathrm{~F}_{5}\right)_{3}$ & 217 & 270 & 251 & -130 \\
$\mathrm{P}-\mathrm{Bn} / 5 \% \mathrm{~B}\left(\mathrm{C}_{6} \mathrm{~F}_{5}\right)_{3}$ & 174 & 248 & 216 & -45 \\
$\mathrm{P}-\mathrm{Bn} / 10 \% \mathrm{~B}\left(\mathrm{C}_{6} \mathrm{~F}_{5}\right)_{3}$ & 163 & 247 & 215 & -74 \\
\hline
\end{tabular}

${ }^{\text {a }}$ DSC thermograms were collected under $20 \mathrm{~mL} \cdot \mathrm{min}^{-1} \mathrm{~N}_{2}$ flow and $10^{\circ} \mathrm{C} \cdot \mathrm{min}^{-1}$ heating rate. 
Previous mechanistic studies concerning Lewis acid catalysed ROP of benzoxazines disclosed the characteristic and two major polymerization mechanism was proposed. Correspondingly, a plausible mechanism for the $\mathrm{B}\left(\mathrm{C}_{6} \mathrm{~F}_{5}\right)_{3}$ promoted ROP is proposed in Scheme 4 . In the case of boron compounds, path I appears to be dominant process when compared to path II, due to the high complexation affinity of $\mathrm{N}$ and $\mathrm{B}$ atoms thus favours the electron transfer from $\mathrm{N}$ to $\mathrm{B}$ in the first step.

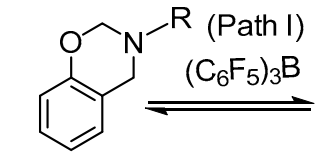

1,3-benzoxazine $(\mathrm{Bz})$

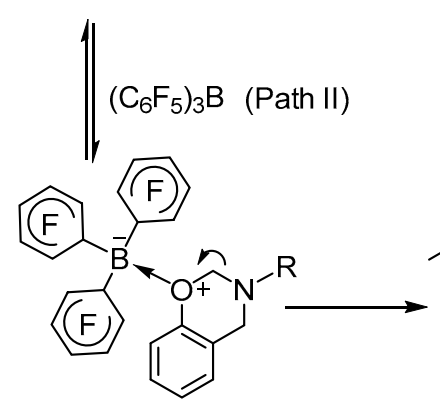

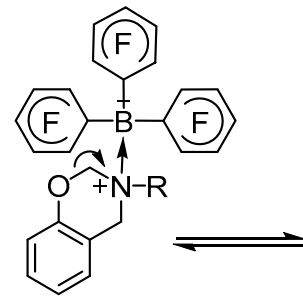
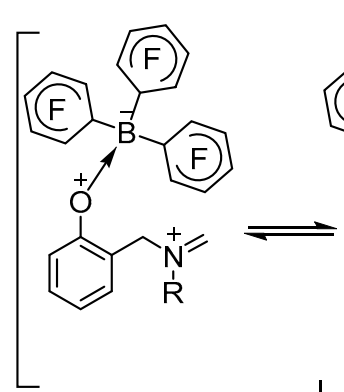<smiles>[R]N([1H])Cc1ccccc1O[C][B-](c1ccccc1)(c1ccccc1)c1ccccc1</smiles>

$\mathrm{E}^{+}$aro
subs.

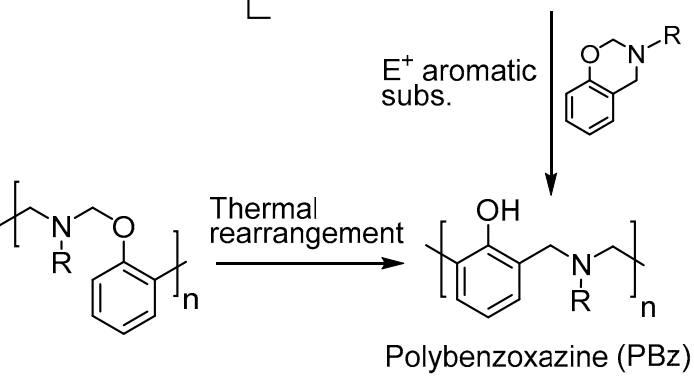

Scheme 4. Tris(pentafluorophenyl)borane catalysed ROP of benzoxazine.

It was shown that linear and soluble polybenzoxazines can be obtained by using mono functional benzoxazines with blocked para position on the phenol moiety. For example, blocking the para position with tertiary butyl groups prevents the attack of carbocation to this position thus avoids crosslinking. Hence, $t$-P-Bt was deliberately selected so as to follow ring-opening reaction by ${ }^{1} \mathrm{H} N M R$. Initially, the solubility of the cured $t$-P-Bt was tested after curing at $220^{\circ} \mathrm{C}$ for $1 \mathrm{~h}$ and the obtained polymer was analysed by GPC using THF as eluent to determine the molecular weight. The GPC chromatogram (Figure S4) showed a molecular weight of $M_{\mathrm{n}}$ : $980 \mathrm{Da}$ with 3.01 polydispersity index. The relatively high dispersity observed is the consequence of the nature of the condensation

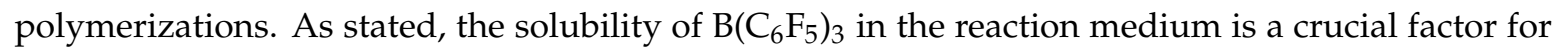
the ring-opening of benzoxazines. It is even likely that ring-opening can be achieved at r.t. in certain solvents. However, it is important to point out that it does not necessarily mean that the overall polymerization can take place at r.t. To test this probability, we have conducted a reaction followed by ${ }^{1} \mathrm{H}$ NMR spectroscopy. ${ }^{1} \mathrm{H}$ NMR spectra of the aliquot samples of the solution of $t$-P-Bt and $\mathrm{B}_{\left(\mathrm{C}_{6} \mathrm{~F}_{5}\right)_{3}}$ ( $5 \mathrm{~mol} \%$ ) in $\mathrm{CDCl}_{3}$ at the beginning and after 30,60, and 120 min were recorded to observe the changes of the signals corresponding to $\mathrm{N}-\mathrm{CH}_{2}-\mathrm{O}$ protons of the oxazine ring. As can be seen from Figure 3 , the intensity of the peak at 4.85 ppm decreases drastically within 30 min., indicating that $\left.\mathrm{B}_{(} \mathrm{C}_{6} \mathrm{~F}_{5}\right)_{3}$ catalyses ring-opening reaction at r.t. in solution medium. These results reveal that the catalyst acts rapidly and starts the ring-opening upon admixing, thus provide clear evidence for the fast curing at higher temperatures. 


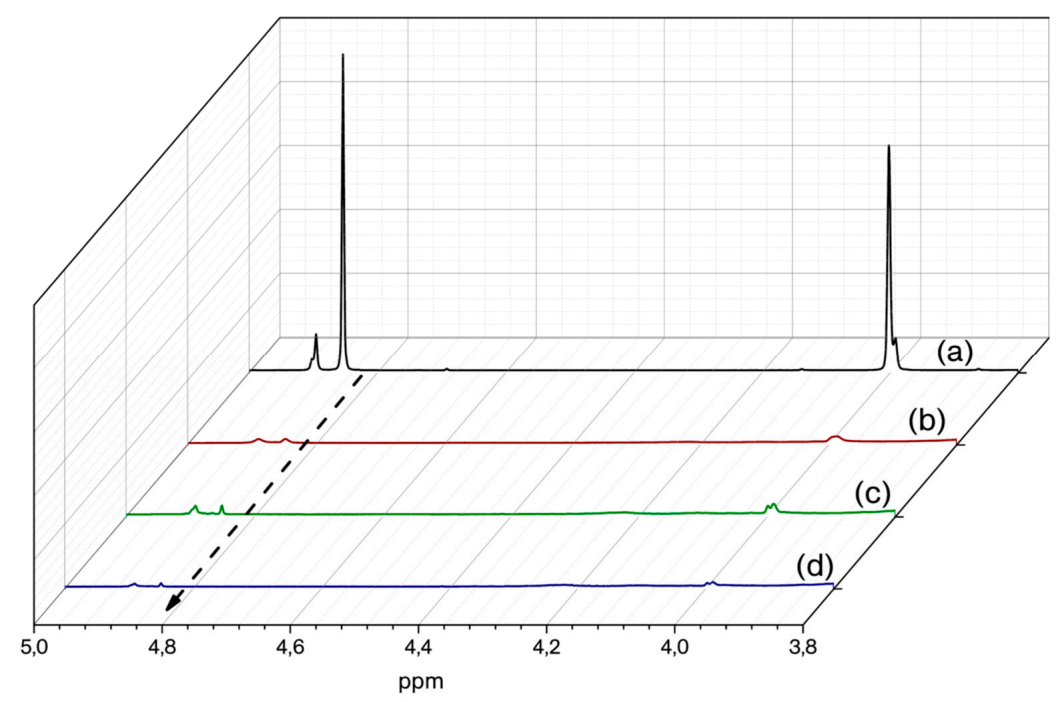

Figure 3. Overlaid ${ }^{1} \mathrm{H}$ NMR spectra of $t-\mathrm{P}-\mathrm{Bt} / 5 \% \mathrm{~B}\left(\mathrm{C}_{6} \mathrm{~F}_{5}\right)_{3}$ mixture as prepared $(\mathbf{a}) ; t-\mathrm{P}-\mathrm{Bt} / 5 \% \mathrm{~B}\left(\mathrm{C}_{6} \mathrm{~F}_{5}\right)_{3}$ mixture after $30 \mathrm{~min}(\mathbf{b}) ; t-\mathrm{P}-\mathrm{Bt} / 5 \% \mathrm{~B}\left(\mathrm{C}_{6} \mathrm{~F}_{5}\right)_{3}$ mixture after $60 \mathrm{~min}(\mathbf{c}) ; t-\mathrm{P}-\mathrm{Bt} / 5 \% \mathrm{~B}\left(\mathrm{C}_{6} \mathrm{~F}_{5}\right)_{3}$ mixture after $120 \min (\mathbf{d})$.

On the other hand, a similar curing study was also performed by using P-Bn monomer, which forms crosslinked polybenzoxazine. Therefore, FTIR spectroscopy was used to track the ring-opening of oxazine ring for certain time intervals (Figure 4). The overlaid FTIR spectra of the resulting products clearly reveals the change on the oxazine ring bands. The intensity of the $\mathrm{C}-\mathrm{O}-\mathrm{C}$ band at $1218 \mathrm{~cm}^{-1}$ is reduced after $30 \mathrm{~min}$ and the reduction becomes more pronounced after $60 \mathrm{~min}$. Moreover, polymerization of benzoxazine resins is generally proved by the disappearance of the band at $960-900 \mathrm{~cm}^{-1}$, corresponding to the $\mathrm{C}-\mathrm{H}$ out-of-plane bending of the benzene and the O-C stretching of the oxazine ring [47]. The intensity of the related band at $926 \mathrm{~cm}^{-1}$ is reduced by time and a new band at $967 \mathrm{~cm}^{-1}$ emerges, evidencing the ring-opening of oxazine by $\mathrm{B}\left(\mathrm{C}_{6} \mathrm{~F}_{5}\right)_{3}$ catalyst.

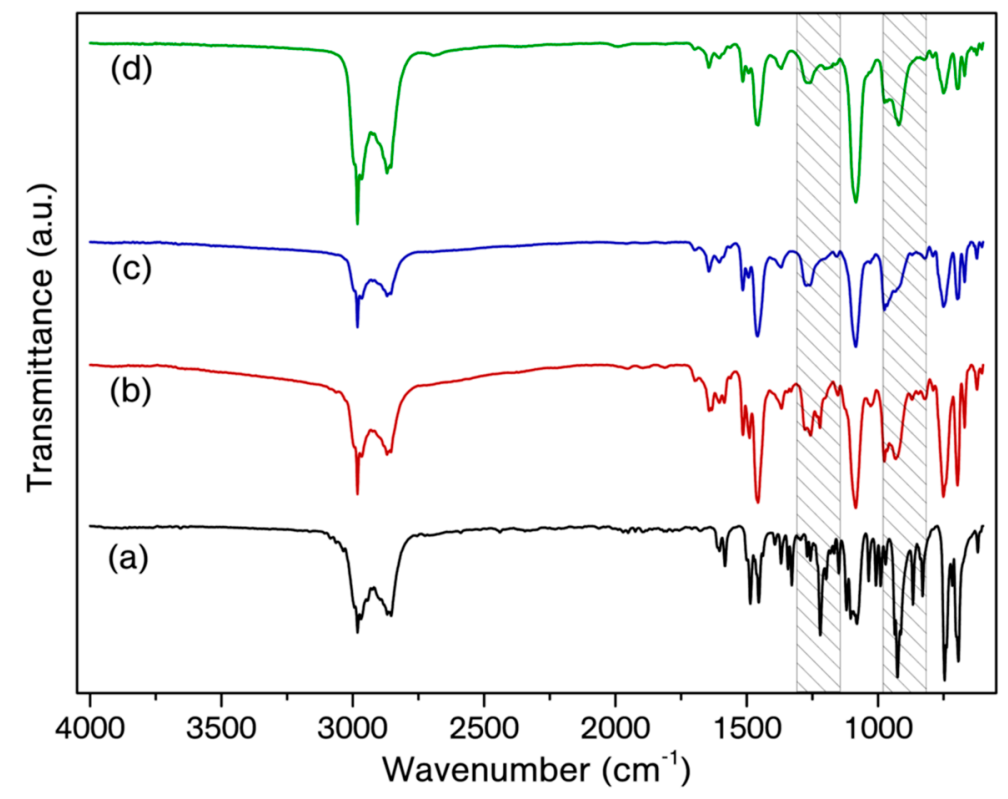

Figure 4. Overlaid FTIR spectra of $\mathrm{P}-\mathrm{Bn} / 5 \% \mathrm{~B}\left(\mathrm{C}_{6} \mathrm{~F}_{5}\right)_{3}$ mixture as prepared (a), $\mathrm{P}-\mathrm{Bn} / 5 \% \mathrm{~B}\left(\mathrm{C}_{6} \mathrm{~F}_{5}\right)_{3}$ mixture after $30 \mathrm{~min}$. (b), $\mathrm{P}-\mathrm{Bn} / 5 \% \mathrm{~B}\left(\mathrm{C}_{6} \mathrm{~F}_{5}\right)_{3}$ mixture after $60 \mathrm{~min}$. (c), $\mathrm{P}-\mathrm{Bn} / 5 \% \mathrm{~B}\left(\mathrm{C}_{6} \mathrm{~F}_{5}\right)_{3}$ mixture after 120 min. (d). 
The thermal stability of the polybenzoxazines for each catalyst ratio was studied by using thermo-gravimetric analysis (TGA). TGA traces and related thermo-gravimetric results are presented in Figures 5 and 6, and Table 2, respectively. Although cured $\mathrm{P}-\mathrm{Bn} / \mathrm{B}\left(\mathrm{C}_{6} \mathrm{~F}_{5}\right)_{3}$ have slight differences for $\mathrm{T}_{5 \%}$, a pronounced effect of the catalyst on the thermal stability for $T_{10 \%}, T_{\mathrm{c}}$ and $T_{\max }$ values is visible. On the other hand, the initial degradation values for cured $\mathrm{B}-\mathrm{a} / \mathrm{B}\left(\mathrm{C}_{6} \mathrm{~F}_{5}\right)_{3}$ are lower than that of the cured pristine B-a. Polybenzoxazines formed from monofunctional benzoxazines generally have low crosslinking degree and the catalyst presumably increases the crosslinking density of polybenzoxazine of P-Bn. In contrast, B-a already produces stiff network due to the difunctional structure, thus any positive effect on initial thermal degradation is not observed. Notably, the addition of $\left.\mathrm{B}_{(} \mathrm{C}_{6} \mathrm{~F}_{5}\right)_{3}$ showed drastic increment in the char yield at $800{ }^{\circ} \mathrm{C}$ for both of the systems. Similar positive effect was also observed for polybenzoxazines obtained by transition metal based catalytic ROP. Although the $\mathrm{B}$ atom is not a transition metal, char yield improvement is significant with $\mathrm{B}\left(\mathrm{C}_{6} \mathrm{~F}_{5}\right)_{3}$ catalyst and only $3 \mathrm{~mol} \%$ addition of $\mathrm{B}\left(\mathrm{C}_{6} \mathrm{~F}_{5}\right)_{3}$ augmented the char yields $11-13 \%$. Three reasons can be discussed to explain this phenomenon. The high degree of crosslinking due to the catalyst, the coordination between boron and nitrogen atoms that may delay the amine degradation in polybenzoxaine, and apart from central boron atom in the catalyst, fluorine atoms may also contribute to this observed effect due to the well-known flame retardation property of aromatic fluorine compounds [48,49].

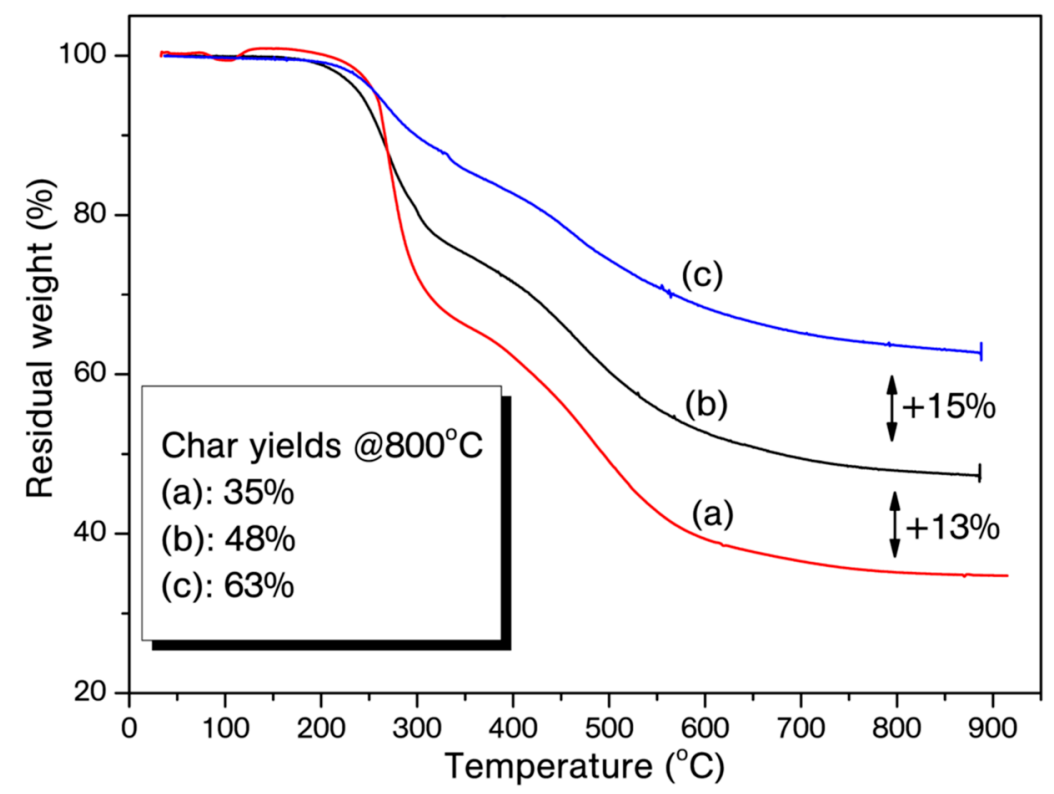

Figure 5. Thermo-gravimetric analysis (TGA) traces of cured $\mathrm{P}-\mathrm{Bn}(\mathbf{a}), \mathrm{P}-\mathrm{Bn} / 3 \% \mathrm{~B}\left(\mathrm{C}_{6} \mathrm{~F}_{5}\right)_{3}(\mathbf{b}), \mathrm{P}-\mathrm{Bn} / 5 \%$ $\mathrm{B}\left(\mathrm{C}_{6} \mathrm{~F}_{5}\right)_{3}(\mathrm{c})$.

Table 2. Thermal properties of the cured P-Bn, B-a and $\mathrm{B}\left(\mathrm{C}_{6} \mathrm{~F}_{5}\right)_{3}$ ( 3 and $5 \mathrm{~mol} \%$ ) mixtures.

\begin{tabular}{ccccc}
\hline Sample & $\boldsymbol{T}_{\mathbf{5} \%}\left({ }^{\circ} \mathrm{C}\right)$ & $\boldsymbol{T}_{\mathbf{1 0} \%}\left({ }^{\circ} \mathrm{C}\right)$ & $\boldsymbol{T}_{\max }\left({ }^{\circ} \mathrm{C}\right)^{\mathbf{a}}$ & $\boldsymbol{T}_{\mathbf{c}}(\mathbf{\%})$ \\
\hline P-Bn & 257 & 267 & $270 *, 466$ & 35 \\
P-Bn $/ 3 \% \mathrm{~B}\left(\mathrm{C}_{6} \mathrm{~F}_{5}\right)_{3}$ & 258 & 263 & $272 *, 492$ & 48 \\
$\mathrm{P}-\mathrm{Bn} / 5 \% \mathrm{~B}\left(\mathrm{C}_{6} \mathrm{~F}_{5}\right)_{3}$ & 244 & 297 & $268 *, 557$ & 63 \\
$\mathrm{~B}-\mathrm{a}$ & 326 & 364 & 390 & 46 \\
$\mathrm{~B}-\mathrm{a} / 3 \% \mathrm{~B}\left(\mathrm{C}_{6} \mathrm{~F}_{5}\right)_{3}$ & 294 & 347 & $284 *, 392$ & 57 \\
$\mathrm{~B}-\mathrm{a} / 5 \% \mathrm{~B}\left(\mathrm{C}_{6} \mathrm{~F}_{5}\right)_{3}$ & 323 & 340 & $271 *, 391$ & 65 \\
\hline
\end{tabular}

a These values extracted from derivative of TGA (Figures S5 and S6 in Supplementary Materials); ${ }^{*}$ Major $T_{\max }$; $T_{5 \%}$ : The temperature for which the weight loss is $5 \% ; T_{10 \%}$ : The temperature for which the weight loss is $10 \%$; $T_{\max }$ : The temperature for maximum weight loss; $T_{\mathrm{c}}$ : The char yield at $800^{\circ} \mathrm{C}$. 


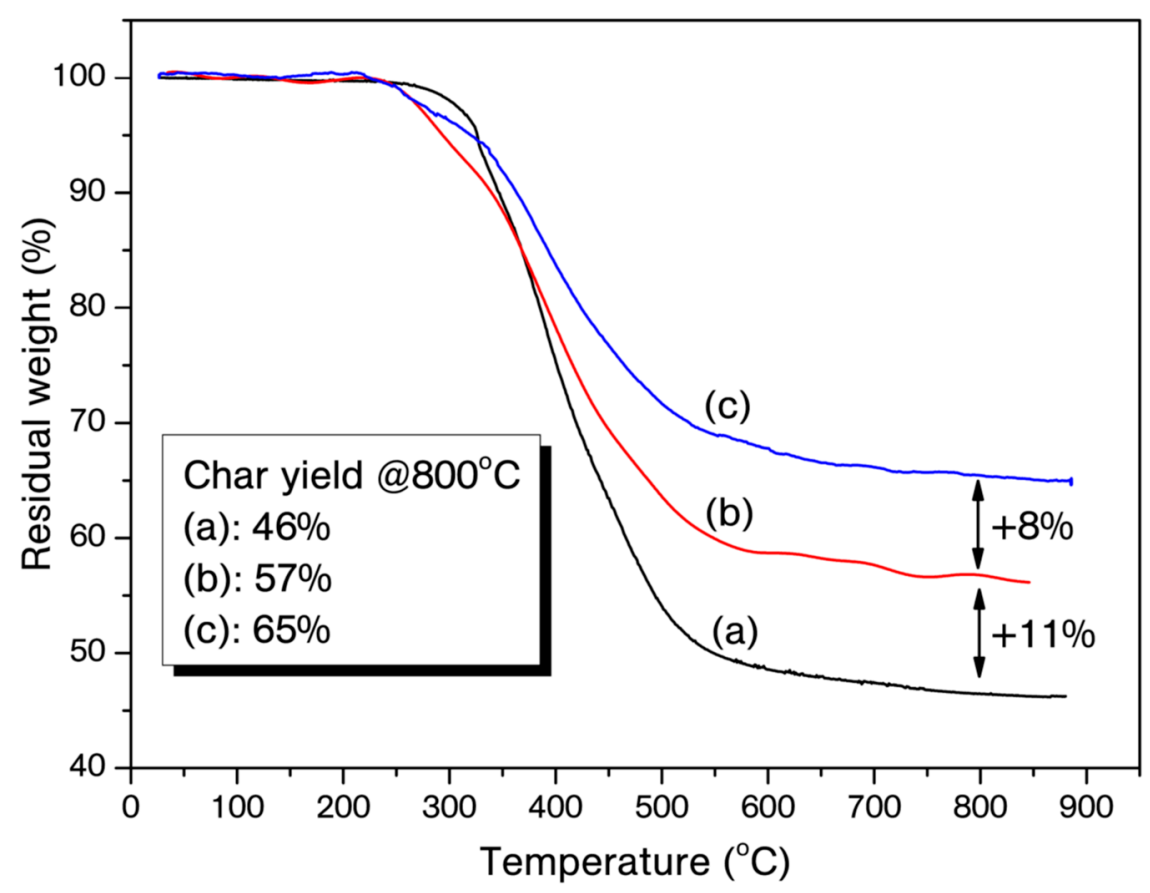

Figure 6. TGA traces of cured B-a (a), B-a/3\% B( $\left.\mathrm{C}_{6} \mathrm{~F}_{5}\right)_{3}(\mathbf{b}), \mathrm{B}-\mathrm{a} / 5 \% \mathrm{~B}\left(\mathrm{C}_{6} \mathrm{~F}_{5}\right)_{3}(\mathbf{c})$.

\section{Conclusions}

We have established the catalytic potential of tris(pentafluorophenyl)borane in the polymerization of benzoxazines. The benzoxazine/catalyst mixtures were easily prepared and the catalyst solubility was high due to the its ligated nature and the strong binding affinity between $\mathrm{N}$ and $\mathrm{B}$ atom. As expected, borane catalyst acted rapidly and initiated the ROP of model benzoxazine compounds, which disclosed that the catalyst is suitable for fast curing demands. The strong catalytic properties of the catalyst exhibited an unusual impact on thermal properties of the resulting polybenzoxazines. Especially, char yield improvement is significant with the catalyst and only $3 \mathrm{~mol} \%$ addition of $\mathrm{B}\left(\mathrm{C}_{6} \mathrm{~F}_{5}\right)_{3}$ augmented the char yields $11-13 \%$. Therefore, this catalyst may find applications where high char yields are required and metal based catalyst impurities would be a drawback.

Supplementary Materials: The following are available online at http:/ / www.mdpi.com/2073-4360/10/3/239/ s1.

Acknowledgments: Authors thank to Istanbul Technical University Research Fund.

Author Contributions: The manuscript was written through contributions of all authors. All authors have given approval to the final version of the manuscript.

Conflicts of Interest: The authors declare no competing financial interest.

\section{References}

1. Ghosh, N.N.; Kiskan, B.; Yagci, Y. Polybenzoxazines-New high performance thermosetting resins: Synthesis and properties. Prog. Polym. Sci. 2007, 32, 1344-1391. [CrossRef]

2. Wirasate, S.; Dhumrongvaraporn, S.; Allen, D.J.; Ishida, H. Molecular origin of unusual physical and mechanical properties in novel phenolic materials based on benzoxazine chemistry. J. Appl. Polym. Sci. 1998, 70, 1299-1306. [CrossRef]

3. Kiskan, B. Adapting benzoxazine chemistry for unconventional applications. React. Funct. Polym. 2017. [CrossRef]

4. Kukut, M.; Kiskan, B.; Yagci, Y. Self-curable benzoxazine functional polybutadienes synthesized by click chemistry. Des. Monomers Polym. 2009, 12, 167-176. [CrossRef] 
5. Lin, R.-C.; Mohamed, M.; Chen, T.; Kuo, S.-W. Coumarin- and carboxyl-functionalized supramolecular polybenzoxazines form miscible blends with polyvinylpyrrolidone. Polymers 2017, 9, 146. [CrossRef]

6. Hu, W.-H.; Huang, K.-W.; Kuo, S.-W. Heteronucleobase-functionalized benzoxazine: Synthesis, thermal properties, and self-assembled structure formed through multiple hydrogen bonding interactions. Polym. Chem. 2012, 3, 1546-1554. [CrossRef]

7. Kim, H.D.; Ishida, H. A study on hydrogen-bonded network structure of polybenzoxazines. J. Phys. Chem. A 2002, 106, 3271-3280. [CrossRef]

8. Dong, H.; Xin, Z.; Lu, X.; Lv, Y. Effect of n-substituents on the surface characteristics and hydrogen bonding network of polybenzoxazines. Polymer 2011, 52, 1092-1101. [CrossRef]

9. Hu, W.H.; Huang, K.W.; Chiou, C.W.; Kuo, S.W. Complementary multiple hydrogen bonding interactions induce the self-assembly of supramolecular structures from heteronucleobase-functionalized benzoxazine and polyhedral oligomeric silsesquioxane nanoparticles. Macromolecules 2012, 45, 9020-9028. [CrossRef]

10. Ishida, H.; Allen, D.J. Physical and mechanical characterization of near-zero shrinkage polybenzoxazines. J. Polym. Sci. B 1996, 34, 1019-1030. [CrossRef]

11. Andronescu, C.; Gârea, S.A.; Deleanu, C.; Iovu, H. Characterization and curing kinetics of new benzoxazine monomer based on aromatic diamines. Thermochim. Acta 2012, 530, 42-51. [CrossRef]

12. Hamerton, I.; McNamara, L.T.; Howlin, B.J.; Smith, P.A.; Cross, P.; Ward, S. Examining the initiation of the polymerization mechanism and network development in aromatic polybenzoxazines. Macromolecules 2013, 46, 5117-5132. [CrossRef] [PubMed]

13. Baqar, M.; Agag, T.; Huang, R.; Maia, J.; Qutubuddin, S.; Ishida, H. Mechanistic pathways for the polymerization of methylol-functional benzoxazine monomers. Macromolecules 2012, 45, 8119-8125. [CrossRef]

14. Chutayothin, P.; Ishida, H. Cationic ring-opening polymerization of 1,3-benzoxazines: Mechanistic study using model compounds. Macromolecules 2010,43, 4562-4572. [CrossRef]

15. Sudo, A.; Kudoh, R.; Nakayama, H.; Arima, K.; Endo, T. Selective formation of poly $(n, o$-acetal $)$ by polymerization of 1,3-benzoxazine and its main chain rearrangement. Macromolecules 2008, 41, 9030-9034. [CrossRef]

16. Endo, T. Toward elucidating the role of number of oxazine rings and intermediates in the benzoxazine backbone on their thermal characteristics. Macromolecules 2016, 49, 8466-8478.

17. Andreu, R.; Reina, J.A.; Ronda, J.C. Carboxylic acid-containing benzoxazines as efficient catalysts in the thermal polymerization of benzoxazines. J. Polym. Sci. A 2008, 46, 6091-6101. [CrossRef]

18. Zuniga, C.; Larrechi, M.S.; Lligadas, G.; Ronda, J.C.; Galia, M.; Cadiz, V. Polybenzoxazines from renewable diphenolic acid. J. Polym. Sci. A 2011, 49, 1219-1227. [CrossRef]

19. Kiskan, B.; Demirel, A.L.; Kamer, O.; Yagci, Y. Synthesis and characterization of nanomagnetite thermosets based on benzoxazines. J. Polym. A 2008, 46, 6780-6788. [CrossRef]

20. Andreu, R.; Reina, J.A.; Ronda, J.C. Studies on the thermal polymerization of substituted benzoxazine monomers: Electronic effects. J. Polym. Sci. A Chem. 2008, 46, 3353-3366. [CrossRef]

21. Soto, M.; Hiller, M.; Oschkinat, H.; Koschek, K. Multifunctional benzoxazines feature low polymerization temperature and diverse polymer structures. Polymers 2016, 8, 278. [CrossRef]

22. Zuniga, C.; Lligadas, G.; Carlos Ronda, J.; Galia, M.; Cadiz, V. Self-foaming diphenolic acid benzoxazine. Polymer 2012, 53, 3089-3095. [CrossRef]

23. Lin, C.H.; Feng, Y.R.; Dai, K.H.; Chang, H.C.; Juang, T.Y. Synthesis of a benzoxazine with precisely two phenolic oh linkages and the properties of its high-performance copolymers. J. Polym. Sci. A 2013, 51, 2686-2694.

24. Zhang, W.; Froimowicz, P.; Arza, C.R.; Ohashi, S.; Xin, Z.; Ishida, H. Latent catalyst-containing naphthoxazine: Synthesis and effects on ring-opening polymerization. Macromolecules 2016, 49, 7129-7140. [CrossRef]

25. Kocaarslan, A.; Kiskan, B.; Yagci, Y. Ammonium salt catalyzed ring-opening polymerization of 1,3-benzoxazines. Polymer 2017, 122, 340-346. [CrossRef]

26. Arslan, M.; Kiskan, B.; Yagci, Y. Combining elemental sulfur with polybenzoxazines via inverse vulcanization. Macromolecules 2016, 49, 767-773. [CrossRef]

27. Semerci, E.; Kiskan, B.; Yagci, Y. Thiol reactive polybenzoxazine precursors: A novel route to functional polymers by thiol-oxazine chemistry. Eur. Polym. J. 2015, 69, 636-641. [CrossRef]

28. Bektas, S.; Kiskan, B.; Orakdogen, N.; Yagci, Y. Synthesis and properties of organo-gels by thiol-benzoxazine chemistry. Polymer 2015, 75, 44-50. [CrossRef] 
29. Sudo, A.; Yamashita, H.; Endo, T. Ring-opening polymerization of 1,3-benzoxazines by p-toluenesulfonates as thermally latent initiators. J. Polym. Sci. A 2011, 49, 3631-3636. [CrossRef]

30. Wang, J.; Xu, Y.Z.; Fu, Y.F.; Liu, X.D. Latent curing systems stabilized by reaction equilibrium in homogeneous mixtures of benzoxazine and amine. Sci. Rep. 2016, 6, 38584. [CrossRef] [PubMed]

31. Sun, J.; Wei, W.; Xu, Y.; Qu, J.; Liu, X.; Endo, T. A curing system of benzoxazine with amine: Reactivity, reaction mechanism and material properties. RSC Adv. 2015, 5, 19048-19057. [CrossRef]

32. Gorodisher, I.; DeVoe, R.J.; Webb, R.J. Catalytic opening of lateral benzoxazine rings by thiols. Handb. Benzoxazine Resins 2011, 211-234. [CrossRef]

33. Dunkers, J.; Ishida, H. Reaction of benzoxazine-based phenolic resins with strong and weak carboxylic acids and phenols as catalysts. J. Polym. Sci. A 1999, 37, 1913-1921. [CrossRef]

34. Kiskan, B.; Yagci, Y.; Sahmethogilu, E.; Toppare, L. Preparation of conductive polybenzoxazines by oxidative polymerization. J. Polym. Sci. A Chem. 2007, 45, 999-1006. [CrossRef]

35. Wang, Y.X.; Ishida, H. Cationic ring-opening polymerization of benzoxazines. Polymer 1999, 40, 4563-4570. [CrossRef]

36. Cid, J.A.; Wang, Y.X.; Ishida, H. Cationic polymerization of benzoxazine monomers by boron trifluoride complex. Polym. Polym. Compos. 1999, 7, 409-420.

37. Sudo, A.; Hirayama, S.; Endo, T. Highly efficient catalysts-acetylacetonato complexes of transition metals in the 4 th period for ring-opening polymerization of 1,3-benzoxazine. J. Polym. Sci. A 2010, 48, 479-484. [CrossRef]

38. Lawson, J.R.; Melen, R.L. Tris(pentafluorophenyl)borane and beyond: Modern advances in borylation chemistry. Inorg. Chem. 2017, 56, 8627-8643. [CrossRef] [PubMed]

39. Fasano, V.; Radcliffe, J.E.; Ingleson, M.J. Mechanistic insights into the b(c6f5)3-initiated aldehyde-aniline-alkyne reaction to form substituted quinolines. Organometallics 2017, 36, 1623-1629. [CrossRef]

40. Erker, G. Tris(pentafluorophenyl)borane: A special boron lewis acid for special reactions. Dalton Trans. 2005, 1883-1890. [CrossRef] [PubMed]

41. Hansmann, M.M.; López-Andarias, A.; Rettenmeier, E.; Egler-Lucas, C.; Rominger, F.; Hashmi, A.S.K.; Romero-Nieto, C. B(c6f5)3: A lewis acid that brings the light to the solid state. Angew. Chem. Int. Edit. 2016, 55, 1196-1199. [CrossRef] [PubMed]

42. Huang, W.; Besar, K.; LeCover, R.; Rule, A.M.; Breysse, P.N.; Katz, H.E. Highly sensitive nh3 detection based on organic field-effect transistors with tris(pentafluorophenyl)borane as receptor. J. Am. Chem. Soc. 2012, 134, 14650-14653. [CrossRef] [PubMed]

43. Hamilton, C.W.; Baker, R.T.; Staubitz, A.; Manners, I. B-n compounds for chemical hydrogen storage. Chem. Soc. Rev. 2009, 38, 279-293. [CrossRef] [PubMed]

44. Imran, M.; Kiskan, B.; Yagci, Y. Concise synthesis and characterization of unsymmetric 1,3-benzoxazines by tandem reactions. Tetrahedron Lett. 2013, 54, 4966-4969. [CrossRef]

45. Wang, X.; Chen, F.; Gu, Y. Influence of electronic effects from bridging groups on synthetic reaction and thermally activated polymerization of bisphenol-based benzoxazines. J. Polym. Sci. A Chem. 2011, 49, 1443-1452. [CrossRef]

46. Demir, K.D.; Kiskan, B.; Yagci, Y. Thermally curable acetylene-containing main-chain benzoxazine polymers via sonogashira coupling reaction. Macromolecules 2011, 44, 1801-1807. [CrossRef]

47. Han, L.; Iguchi, D.; Gil, P.; Heyl, T.R.; Sedwick, V.M.; Arza, C.R.; Ohashi, S.; Lacks, D.J.; Ishida, H. Oxazine ring-related vibrational modes of benzoxazine monomers using fully aromatically substituted, deuterated, 15n isotope exchanged, and oxazine-ring-substituted compounds and theoretical calculations. J. Phys. Chem. A 2017, 121, 6269-6282. [CrossRef] [PubMed]

48. Achiha, T.; Nakajima, T.; Ohzawa, Y.; Koh, M.; Yamauchi, A.; Kagawa, M.; Aoyama, H. Thermal stability and electrochemical properties of fluorine compounds as nonflammable solvents for lithium-ion batteries. J. Electrochem. Soc. 2010, 157, A707-A712. [CrossRef]

49. Dhara, M.G.; Banerjee, S. Fluorinated high-performance polymers: Poly(arylene ether)s and aromatic polyimides containing trifluoromethyl groups. Prog. Polym. Sci. 2010, 35, 1022-1077. [CrossRef] 
(C) 2018 by the authors. Licensee MDPI, Basel, Switzerland. This article is an open access article distributed under the terms and conditions of the Creative Commons Attribution (CC BY) license (http:/ / creativecommons.org/licenses/by/4.0/). 